\title{
Bibliometric Assessment of Research on Risk Attitude of Entrepreneurs
}

\author{
ANDREEA CHIŢIMIEA \\ Bucharest University of Economic Studies, Romania \\ andreea_ch1995@yahoo.com \\ CARMEN NADIA CIOCOIU \\ Bucharest University of Economic Studies, Romania \\ nadia.ciocoiu@man.ase.ro \\ BOGDAN ŞTEFAN STOICA \\ Bucharest University of Economic Studies, Romania \\ stoica.bogdan@yahoo.com \\ ADINA LILIANA PRIOTEASA \\ Bucharest University of Economic Studies, Romania \\ prioteasaadina@gmail.com
}

\begin{abstract}
The influence of the attitude towards risk on decisions that entrepreneurs take in business is a field of major interest reflected by the increasing number of published papers. This article analyzes the publications included in the Web of Science databases over 1991-2019 period and assesses the correlations made by specialists between certain features of risk attitude in entrepreneurship. Multiple information was evaluated: the number of published papers, information about authors and their nationality, the number of citations received by the selected papers. A keyword analysis, including occurrence, co-occurrence (link strength) and links between them and a keywords map was also performed with a software. The utility in using a bibliometric analysis is to help researchers and scholars to identify new research directions regarding the role of risk attitude and the decision-making process in entrepreneurship.
\end{abstract}

Key words: risk, risk attitude, bibliometric analysis, entrepreneurship, entrepreneur

(cc)BY-SA https://doi.org/10.26493/1854-4231.15.3-27

\section{Introduction}

The influence of risk on entrepreneurial activity is undeniable; which is why more and more researchers are analysing its impact, developing methods and methodologies in order to treat risks. The 
specialists argue that there is a correlation between the predisposition towards the risk of the entrepreneurs and the financial performances registered by an enterprise (Yang, Ishtiaq, and Anwar 2018).

Most commonly, entrepreneurship is defined as a process where a new enterprise or new product/service that didn't exist before is created (Draheim 1972). Since the beginning of the researches into entrepreneurship, there have been authors who relate this field to risk, such as Cantillon (2010), Knight (1921), Kirzner (1973), Kihlstrom and Laffont (1979). More recently, many authors relate the success of a business to the risk attitude of the entrepreneur. These authors include Cliff (1998), Caliendo, Fossen, and Kritikos (2010), Brustbauer (2014), Yang, Ishtiaq, and Anwar (2018), Hanggraeni et al. (2019), Bartolacci, Caputo, and Soverchia (2020).

Through this paper, structured in four chapters (introduction, literature review, research methodology and data collection, results and discussion, conclusions), the authors want to highlight the importance of the attitude towards risk in entrepreneurship. Within this bibliometric analysis the authors analysed the studies carried out by scientific researchers that were published in journals and volumes of conferences indexed in the Web of Science database.

\section{Literature Review}

Specialized literature defines entrepreneurship in various forms, but still having distinct approaches in the view of those who research this subject. In the matter regarding the correlation between risk and entrepreneurial activity, the studies show that the correlation is accepted and recognized by all specialists. Thus, the entrepreneurs attitude towards risk is considered an important aspect in the conduct of the entrepreneurial activity (Cramer et al. 2002), numerous studies are being carried out regarding the predisposition of the entrepreneurs to the risk and the performances registered by them (Brustbauer 2014; Yang, Ishtiaq, and Anwar 2018; Bartolacci, Caputo, and Soverchia 2020; Hanggraeni et al. 2019).

The controversies created by the financial performances obtained by the companies have led to the reorientation of more people towards a career as entrepreneurs, but also to the emergence of a new typology of entrepreneurs who divide their time between the tasks of being an employee and the ones from being an entrepreneur in order to minimize their risks (Burmeister-Lamp, Lévesque, and Schade, 2012).

A considerable number of studies (3770o according to Google 
Scholar) have been researching the behavioural traits that distinguish entrepreneurs from other people. A part of the literature investigates the attitude of entrepreneurs towards uncertainty. The existing theories predicts that those involved in entrepreneurial activities tend to have a distinct attitudes toward risk compared to those who are mere employees (Folta, Delmar, and Wennberg 2010).

The impact of the risk on the entrepreneurial activity generated the emergence of a type of entrepreneur defined by the specialists in this field as 'hybrid entrepreneur.' According to Inc. Magazine, since 1995, a common practice among new entrepreneurs is to carry out the entrepreneurial activity concurrently while being an employee within another company. Experts in this field have stated that this practice is a result of the new entrepreneurs' need to reduce the risks they are exposed to (Burmeister-Lamp, Lévesque, and Schade 2012). This type of entrepreneurs, which has emerged as a direct effect of the risk impact, manages the time given to the company according to the attitude towards the risk (Burmeister-Lamp, Lévesque, and Schade 2012). The authors of this new typology of entrepreneurs say that the entrepreneur with a predisposition to risk allocates more time to the company than a risk-reliant new entrepreneur. Also, these entrepreneurs are known for their desire to analyse the market of commercialized products/services, but also for the fact that they test their entrepreneurial skills according to the specific risks of the activity carried out (Folta, Delmar, and Wennberg, 2010).

More recent research shows that the age (Elam et al. 2019), gender of the entrepreneur (Dawson and Henley 2015) and experience in the market (Bosma et al. 2016) significantly contribute to the predisposition towards the risk of the entrepreneur.

Regarding the level of experience, it mainly influences the decisions taken under conditions of uncertainty. Depending on the decisions made under risk conditions, the types of entrepreneurs are distinguished (those who have an aversion for risks and those who are predisposed to it). By decisions taken under uncertainty and high risk the literature means taking decisions in a short period of time, based on reduced information, frequent changes in the structural variables or in the economic environment in which the company operates. Given these aspects, there are no two decision-makers who have the same quantitative perception, the same degree of knowledge or the same personal opinions. Therefore, these types of decisions are most often influenced by the entrepreneur's emotions and goals (Michl et al. 2009).

An interesting aspect about the influence of risks in entrepreneurial 
activity is found in the study conducted in Burmeister-Lamp, Lévesque, and Schade (2012), in which the authors of the paper analysed a mixed group of students and entrepreneurs and concluded that in the case of students, regardless of their gender, the time allocated by them would decrease when the company recorded the desired financial performance. However, younger entrepreneurs, unlike the older ones, tend to be less risk-averse, especially if the financial results are in line with their goals. This determines the risk attitude of the entrepreneur based on the correlation between the risk and the income that the company can record.

However, a crucial aspect in making decisions in conditions of uncertainty is the entrepreneur's abilities (Caliendo, Fossen, and Kritikos 2006) that do not always depend on the entrepreneur's gender, age or the domain of activity of the company. Meaning, the probability that the decision taken will result in an low income or to even turn into losses is significantly reduced depending on the entrepreneurial abilities of the person how's making the decision, and the implications of the risks assumed are minor. A comparative analysis of the level of risk assumed by different entrepreneurs working in the same field, same area and with the same entrepreneurial skills, but with different levels of experience in the field of activity, revealed significant differences in the generated results, and the impact on the results is correlated strictly with the decision maker (Caliendo, Fossen, and Kritikos 2006).

Block, Sander, and Spiegel (2015) concluded based on their study that entrepreneurs who have reoriented themselves to such a career out of necessity are more risk-averse, and those who are motivated by creativity and innovation are more at risk.

The entrepreneurs risk attitude influences the whole life cycle of the company's. While recent research analyses and formulates theoretical proposals on the positive correlation between the risk attitude and the decision to become an entrepreneur, the effects of external factors (such as environment changes, legislation, market changes etc.) on the survival of an enterprise are not considered simple (Caliendo, Fossen, and Kritikos 2010).

However, there are also specialists who say that the entrepreneurs risk attitude does not significantly influence the performance of the company, and the registered profit is does not increase based on the risky attitude (Rauch and Frese 2007).

Contradictory to those studies, are some papers based on the relationship between the profile of entrepreneurs and the company's financial performance. Caliendo, Fossen, and Kritikos (2010) tested 
this hypothesis and concluded that the entrepreneurs risk attitude is a defining factor for the survival of a business. They stated that only long-term entrepreneurs or those with a low level of risk tolerance resist the market for a long time. From a financial point of view, some studies have shown that the financial rate of return of enterprises run by entrepreneurs with an average level of risk tolerance decreases by about $40 \%$ compared to entrepreneurs with a predisposition to risk or those who are risk-averse (Cramer et al. 2002; Block, Sander, and Spiegel 2015).

The economic and financial implications of the entrepreneurs risk attitude are a subject of continuous debate and research, even if the impact, regardless of the degree of influence, is confirmed by many specialists to be affecting the enterprises activity. This correlation is deepened by the researchers even in the analysis of the personality of the entrepreneurs in order to establish some traits of potential entrepreneur based on the reluctance/predisposition to risk. (Block, Sander, and Spiegel 2015).

Regarding the utility of the bibliometric analysis and the systematic review type analysis to assess the influence of the attitude towards risk in entrepreneurship, we note the studies of Thananusak (2019), who appreciated that since mid-1990 the analysis of the influence of entrepreneurship in the economy has intensified, and the impact of attitude towards risk in sustainable development; Aparicio, Iturralde, and Maseda (2019), who highlighted the impact of entrepreneurial education on entrepreneurship risk attitude, and Georgalos (2017), who does an extensive review of the correlation between entrepreneurship decision-making and risk attitude.

This paper aims to analyse the extent to which the relationship between risk attitude and entrepreneurship is reflected in the literature. In order to carry out this analysis, the authors have followed the evolution of the published papers on the risk attitude of the entrepreneurs at global level during the period 1990-2019. As a research method the authors used the bibliometric analysis.

\section{Research Methodology and Data Collection}

The bibliometric analysis evaluates the interest of the specialists granted to a certain field on the basis of a complex and complete data source that offers a perspective on a period of time from which the scientific researchers began to deepen the targeted field. At the same time, through this type of analysis we appreciate many other information such as: number of published studies, information about authors (nationality), type of papers (article, proceedings paper, re- 
view, book chapter etc.), but also the number of citations the papers received. Currently, this type of analysis is used to assess the correlations made by many specialists between certain specific features of a domain (Servantie et al. 2016; Zheng 2018; Dan and Goia 2018; Berbegal-Mirabent, Alegre, and Ribeiro-Soriano 2018; Dionisio 2019; Lampe, Kraft, and Bausch 2019; Gora 2019).

The research methodology consists in studying the Web of Science database in order to extract and synthesize relevant information from the generated results. The authors have chosen this database for its international recognition of the quality of the published and indexed papers. The generated results were filtered in order to analyse only articles, proceedings paper and reviews, and the results obtained subsequently were evaluated according to the number of published papers, the authors of the studies, the authors nationality, the countries that generated the largest number of studies, the publication period of the resulted studies, the number of citations, the fields and industry of research, but also the sources of publication. The research also includes keyword analysis including occurrence, co-occurrence and links between them and a keywords map.

By searching in January 2020 in the Web of Science database for the keywords 'entrepreneurship' and 'risk attitude' in the topic, from January 1991 until December 2019 were displayed a number of 318 publications, which filtered counted 300 studies based on which was done this study. Furthering the analyses on those publications revealed an overlap of five studies by Clarivate (the total of articletype studies, proceedings paper and review after filtering was 300). The following papers were indexed as articles and proceedings paper 'Uncertainty Avoidance and the Rate of Business Ownership across 21 OECD Countries, 1976-2004' (Wennekers et al. 2007), 'Competitive in the Lab, Successful in the Field?' (Berge et al. 2015), 'A Design Thinking Approach to Introduce Entrepreneurship Education in European School Curricula' (Val et al. 2017), 'What Drives Entrepreneurship in Digital Economy? Evidence from China' (Yin et al. 2019), and Entrepreneurial Intentions of Students in Poland in the View of Ajzen's Theory of Planned Behaviour' (Wach and Wojciechowski 2016).

\section{Results and Discussion}

ANALYSIS OF THE SELECTED PAPERS

This analysis resulted in a number of 300 papers, which was reduced to 295 articles, reviews and proceedings paper as a result of Clari- 
vate's double indexation of five studies as articles and proceedings papers. Thus, the number of studies indexated as proceedings was reduced from 59 to 55. According to the selected data, the largest share on the market of scientific researches is held by articles, which have a number of 234 publications (79.32\%), and in the minority percentage are publications from the proceedings paper (55 studies $18.64 \%$ ) and review (6 studies $-2.03 \%$ ).

Regarding the research based on entrepreneurship, the basis of this area of interest has been laid since the trading period, but the very notion of entrepreneurship appeared in 1755, first mentioned by Cantillon Richard, an illustrious economist known for his many contributions to the economy (Chiţimiea et al. 2019).

Further researches has been done on this field since 1990 after specialists found out the vital role of the entrepreneurs in the sustainable development of the economy of a region/country.

Figure 1. highlights the state of the research conducted on the entrepreneurs risk attitude on annual level. The graphic shows an upward trend in the number of studies carried out, which is in line with the continuous economic development and the agenda of the European Union authorities on entrepreneurship development. Between 1991 and 2011 the studies published in this field recorded an average of 3 publications/year, the maximum being 7 publications. Subsequent to 2011, the interest in entrepreneurship was stimulated by the emergence of external financing programs, and with the infusion of start-up companies, the research done in the field of risk management and the entrepreneurs risk attitude has intensified. Analysing the period 2011-2012, there is an increase in the number of studies of 12 publications (4.07\%), and from 2013 until 2019 the average of studies has increased to 32 publications/year. The greatest impact in the research on the correlation between the risk attitude and entrepreneurship was registered in 2019. However, the number of published studies has increased significantly since 2016, when it almost doubled (41 published studies in 2016 compared to 25 studies in 2015). The interest in the correlation between the level of risk tolerance, the attitude towards it and the successful entrepreneurs led to deepening the field, and in 2019, the number of published studies exceeded the level of 2016 (46 published studies).

The dispersion of domains in which the analysed studies are classified is presented in figure 2. The highest weight in the areas of interest is occupied by the business field (114 studies), followed by management (98 studies) and economy (85 studies). These results are supported by the fact that risk management is a prerogative for 


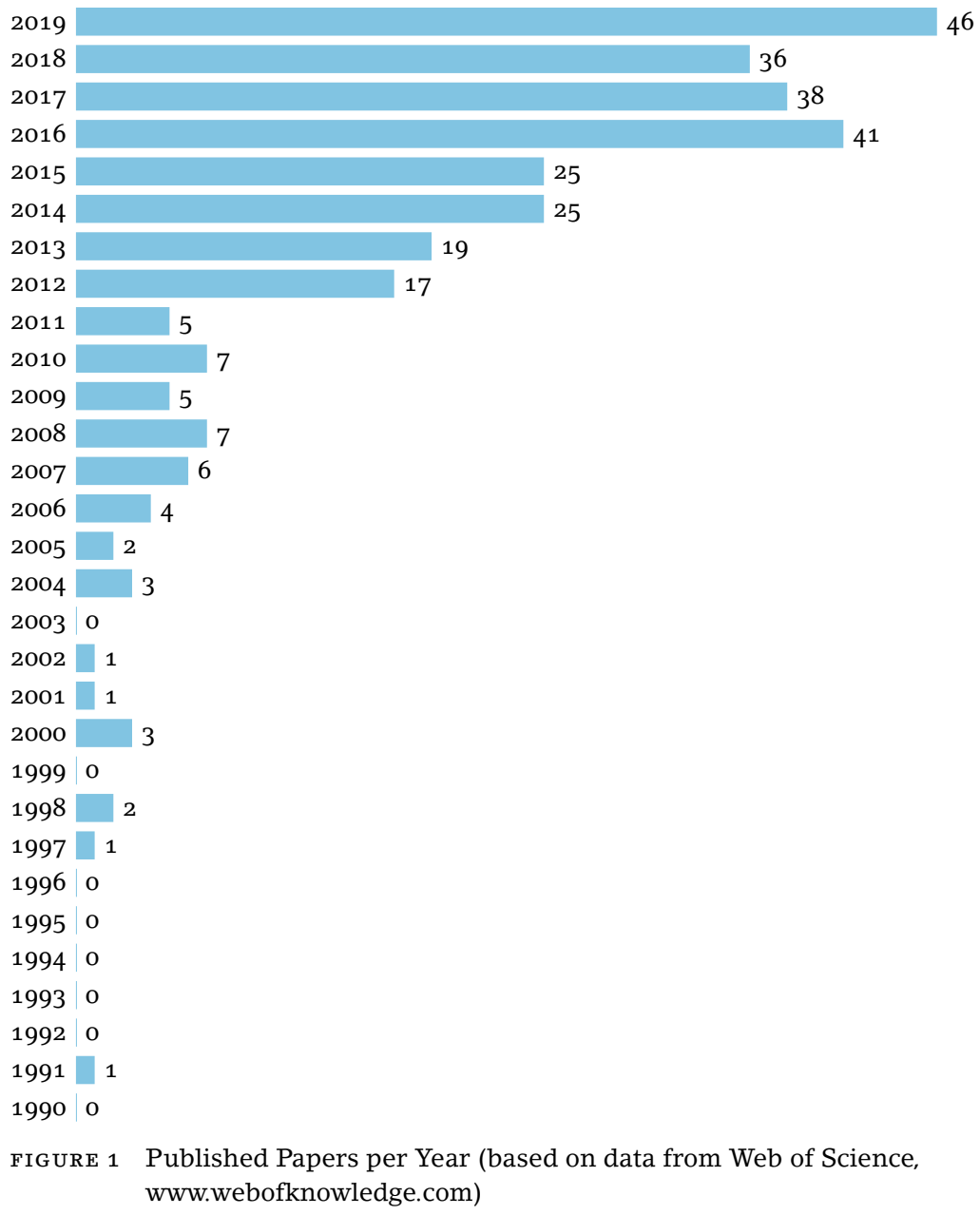

those areas. The domains with relatively large number of published studies include the educational system (32 papers), psychology (12 papers) and ecology (11 papers). The statistics are justified by the fact that the influence of education and personal characteristics on the attitude towards risk is recognized. With regard to ecology, the published studies deal with the interaction between risk and environmental factors. In contrast, in the analysis were also highlighted the areas in which the number of published studies were few. These include: scientific disciplines (4 studies), forestry (3 studies), ethics (3 studies) geography (2 studies), chemistry (2 studies), engineering (2 studies). 


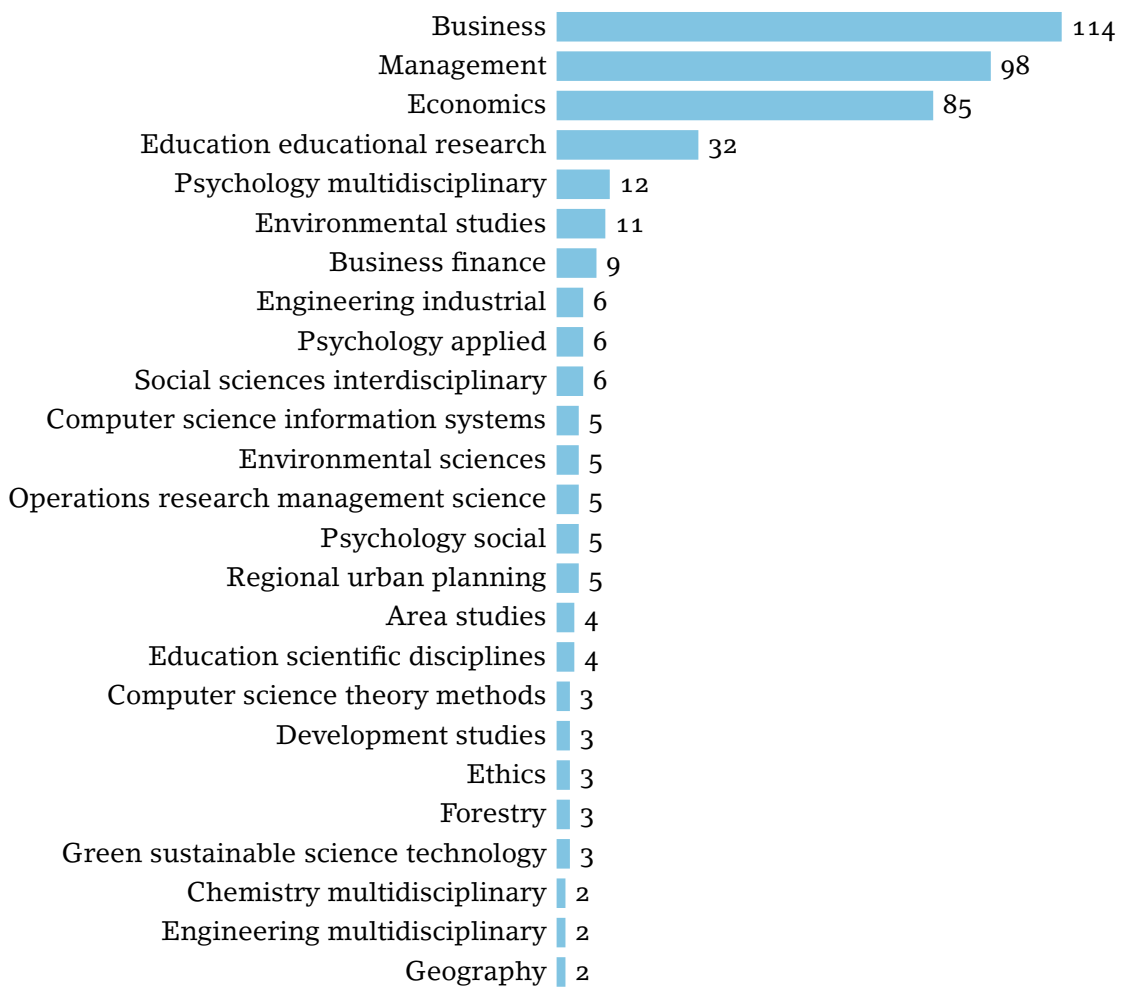

FIGURE 2 The Research Areas on Basis of the Number of Published Articles (Based on data from Web of Science, www.webofknowledge.com)

The number of researchers and the studies carried out aimed at this field is increasing, and the contributions to the scientific environment by each region.

In the next phase of this study, we will refer to the continents Europe and Asia as Eurasia due to Russia presence in statistics, a country that is located in both the continents mentioned, and furthering the analyses we will detail the contribution of these two continents separately.

The largest share is held by studies from authors from Eurasia (78.05\%), followed by those in America (16.83\%). The lowest weights were obtained by Africa (3.41\%) and Oceania (1.71\%). The discrepancy between the number of studies carried out in Eurasia and the rest of the areas is due to the structure of the analysed continents. In Eurasia were included the 30 countries from the European area whose contribution registered 253 studies $(79.06 \%$ of the total of 320 studies), the papers carried out in the Asian space that contribute to 


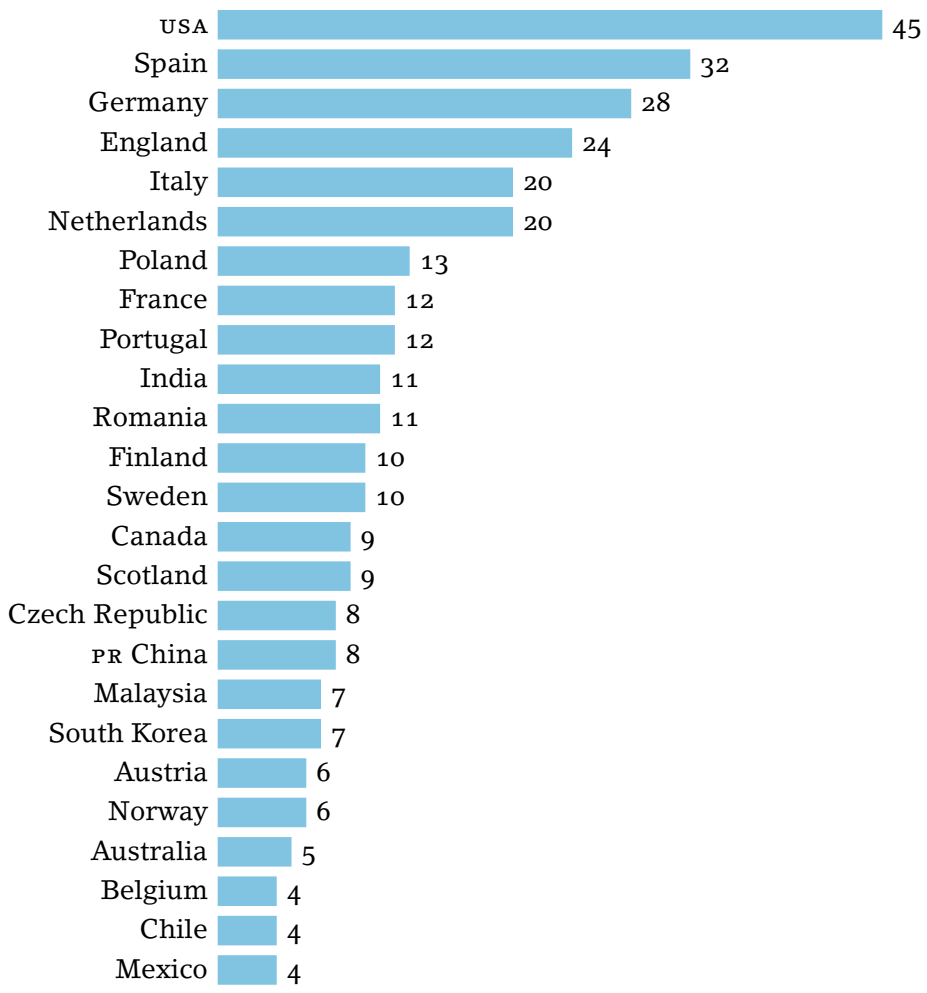

FIgURE 3 Distribution of Papers by Country to Which the Authors Are Affiliated (based on data from Web of Science, www.webofknowledge.com)

this analysis registered a number of 64 studies $(20 \%$ of the total of 320 studies), and also those from Russia (3 studies, about $0.94 \%$ of the 320 total studies).

Analyzing the countries' contributions, the largest number of studies is held by the United States of America, with the majority percentage of $14 \%$, followed by Spain, with $10 \%$ (figure 3). Given that 286 of the studies are done in English (96.95\%) and 7 papers (2.37\%) are in Spanish, the presence of these two countries in the first two positions is explained. There is also a paper published in Russian (0.34\%) and a paper in Polish (0.34\%), but Russia is not among the countries with the highest number of contributions, while Poland has a weight of $4 \%$. Other countries whose contributions were notable include Germany (9\%), England (7\%), Holland and Italy (6\%), France and Portugal (4\%), Romania, Canada and India (3\%). There are also countries with lower weights such as Austria (2\%), Australia (2\%), Belgium (1\%), Chile (1\%) and Mexico (1\%) (figure 3). The statis- 
TABLE 1 The 25 Journals with the Largest Number of Publications

\begin{tabular}{|c|c|c|}
\hline Source titles & $(1)$ & $(2)$ \\
\hline Small Business Economics & 9 & 3.05 \\
\hline International Entrepreneurship and Management Journal & 8 & 2.71 \\
\hline Journal of Business Venturing & 8 & 2.71 \\
\hline Journal of Economic Behavior Organization & 6 & 2.03 \\
\hline Procedia Social and Behavioral Sciences & 6 & 2.03 \\
\hline $\begin{array}{l}\text { Proceedings of the European Conference on Entrepreneurship } \\
\text { and Innovation }\end{array}$ & 6 & 2.03 \\
\hline Journal of Economic Psychology & 5 & 1.69 \\
\hline International Business Review & 4 & 1.36 \\
\hline International Journal of Entrepreneurial Behavior Research & 4 & 1.36 \\
\hline Journal of Technology Transfer & 4 & 1.36 \\
\hline Applied Economics Letters & 3 & 1.02 \\
\hline Contributions to Management Science & 3 & 1.02 \\
\hline Economic Research & 3 & 1.02 \\
\hline Education and Training & 3 & 1.02 \\
\hline Entrepreneurial Business and Economics Review & 3 & 1.02 \\
\hline Entrepreneurship Research Journal & 3 & 1.02 \\
\hline Forest Policy and Economics & 3 & 1.02 \\
\hline Journal of International Entrepreneurship & 3 & 1.02 \\
\hline Journal of Small Business and Enterprise Development & 3 & 1.02 \\
\hline Journal of Small Business Management & 3 & 1.02 \\
\hline $\begin{array}{l}\text { Proceedings of the gth European Conference on Innovation } \\
\text { and Entrepreneurship ECIE } 2014\end{array}$ & 3 & 1.02 \\
\hline Sustainability & 3 & 1.02 \\
\hline $\begin{array}{l}\text { 2nd Cyprus International Conference on Educational Research } \\
\text { CY ICER } 2013\end{array}$ & 2 & 0.68 \\
\hline Annals of Regional Science & 2 & 0.68 \\
\hline Asia Pacific Journal of Innovation and Entrepreneurship & 2 & 0.68 \\
\hline
\end{tabular}

Nотеs Column headings are as follows: (1) number of records, (2) percentage of 295. Based on data from Web of Science (www.webofknowledge.com).

tics is influenced by the fact that most publications indexed in Web of Science are in English, regardless of the country of origin.

This bibliometric analysis also included the journals whose contribution had a significant impact in the field of research. From the total of journals that are indexed IsI, within this analysis were highlighted the first 25 journals with the largest number of papers researching the correlation between 'entrepreneurship' and 'risk attitude' (table 1). The ranking includes twenty-one journals and four volumes of conferences with a representative number of papers. 


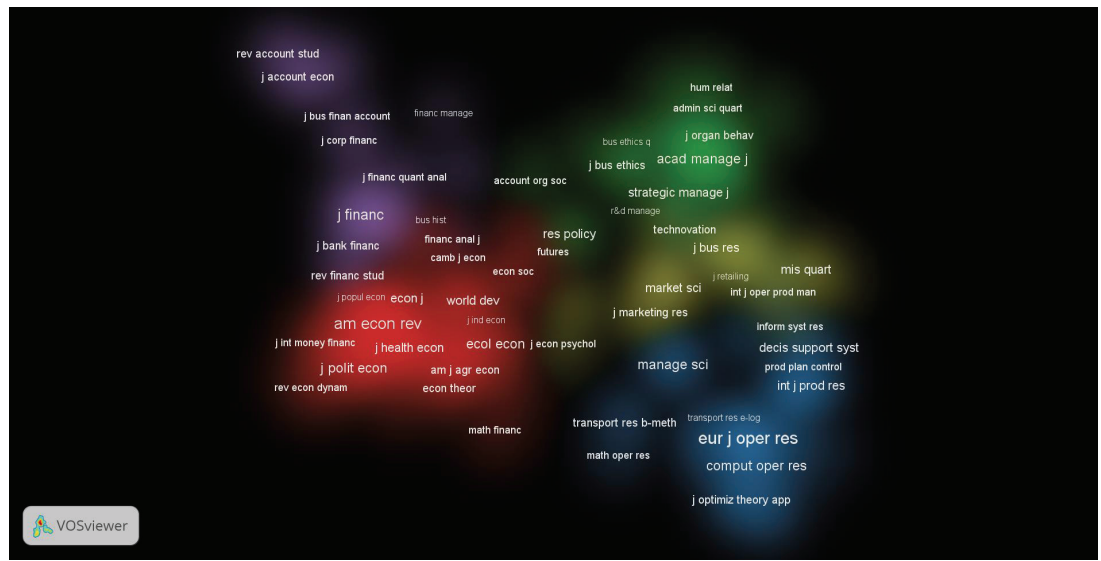

FIGURE 4 Cluster Chart of the Analyzed Journals (created with the vosviewer)

Furthering in this study, the authors have made a visual representation of the journals density was made based on the vosviewer program. In this type of view, journals are represented according to the density of the number of publications they have in the respective fields. The colours of this representation vary from green to yellow (Jan Van Eck and Waltman 2019).

An analysis carried out using the vosviewer program based on the cluster density of the journals has resulted after filtering the studies has reveal the results from the graph obtained in figure 4 . The density visualization based on the cluster analysis is possible only if the articles were grouped on clusters. This type of density visualization (cluster) is similar to the element density visualization, the only exception being the fact that the density of the items is displayed separately for each group of analysed elements (Jan Van Eck and Waltman 2019). The colour of a point within this visualization is obtained by mixing the colours of the different clusters, and the colour intensity is generated by the number of journals belonging to that cluster. Also, the larger the number of journals around the node and respectively, the greater the density of the other journals (they have a greater number of published papers), the closer the colour of the node is to yellow. Conversely, if the number of journals around is reduced and the density of those journals is reduced, the respective node may have a blue colour.

Within this analysis the number of publications of the journals was evaluated according to the research field, and as shown in figure 4 , the program grouped the journals into 5 clusters. Thus, the clus- 
TABle 2 Top 15 Authors and Institutions with the Most Contributions Targeted by the Analysis

\begin{tabular}{llrr}
\hline Authors & Institutions & $(1)$ & $(2)$ \\
\hline Thurik & Erasmus University Rotterdam & 4 & 1.36 \\
Fossen & University of Nevada Reno & 4 & 1.36 \\
Dimitratos & University of Glasgow & 3 & 1.02 \\
Nybakk & Kristiania University College & 3 & 1.02 \\
Rodrigues & Universidade do Minho & 3 & 1.02 \\
Van Der Zwan & Erasmus University Rotterdam & 3 & 1.02 \\
Vieira & Universidade do Minho & 3 & 1.02 \\
Arat & Pamukkale University & 2 & 0.68 \\
Bartos & Masaryk University Brno & 2 & 0.68 \\
Bernat & University of Szczecin & 2 & 0.68 \\
Block & Universitat Trier & 2 & 0.68 \\
Bonilla & Universidad de Chile & 2 & 0.68 \\
Brown & University of Sheffield & 2 & 0.68 \\
Caliendo & University of Potsdam & 2 & 0.68 \\
Cepel & Ligs Univ LLc Honolulu & 2 & 0.68 \\
\hline
\end{tabular}

Notes Column headings are as follows: (1) number of records, (2) percentage of 287. Based on data from Web of Science (www.webofknowledge.com).

ters whose weight is significant are those in the economic area (red) whose category registers 109 journals, the clusters from the management area (green) whose category contains 44 journals and the cluster in the research-development area (blue) which contains 33 journals. The smallest contributions can be found in the marketing area (yellow) with 26 journals and the financial area (purple) with 20 journals. Therefore, the journals in the marketing area had a larger number of journals around them (the management journals being larger and with a significantly higher number of publications), and the journals in the research-development area were more numerous; larger than those in the marketing area (33 journals compared to 26 journals) and had a smaller number of publications compared to those in the other areas.

Regarding the most published authors, the first two positions in the ranking are occupied by Associate Professor Frossen Frank M., Professor of Management at the University of Nevada Reno, and by PhD. Prof. Thurik Roy, Professor of Entrepreneurship and Economics at Montpellier Business School in France, Professor of Entrepreneurship and Economics at Erasmus University Rotterdam, and also Professor of Entrepreneurship for Small and Medium Enterprises at the School of Business and Economics, Free University 
Amsterdam. The contribution of both researcher had a weight of $1.36 \%$ (4 papers) each. The following five positions are occupied by researchers who had a weight of $1.02 \%$ (3 papers). Among them are: PhD. Prof. Dmitratos Pavlos (Professor of Management at the University of Glasgow), PhD. Prof. Rodrigues Cristina (Minho University, Portugal). The smallest weights, according to table 2 , are $0.68 \%$ (2 papers).

\section{CITATION ANALYSIS}

An important aspect of this bibliometric analysis is the number of citations. This is one of the main criteria according to which the contribution of the published studies in a research field is determined.

Starting with 1990, the beginning year of the studies realized on entrepreneurship (Thananusak 2019), the number of published studies was very small (4 papers in the period 1991-1998), which is why we can explain the small number of citations in the period 1991-1998. According to figure 5, the development of entrepreneurship is direct result for the increase of the number of studies, impact observed also in the increasing number of citations. Regarding the 4 studies published in the period 1991-1998, there has been found a very big difference in the number of citations. Thus, Andrews (1991) had only 2 citations form 1991 until 2019, and Pehu, Avotie, and Lasonen ('Training Needs in Entrepreneurial Leadership for Women: Cases from North and South,' 1997) had none. In the other two cases, 327 - 'Exploring the Relationship between Attitudes towards Growth, Gender, and Business Size' (Cliff 1998) - and 894 citations were recorded - 'Does Entrepreneurial Self-Efficacy Distinguish Entrepreneurs from Managers?' (Chen, Greene, and Crick 1998). The interest in the influence of entrepreneurship risk attitude has continued to grow, and the impact on the citation is most noticeable in the period 2016-2019 (figure 5). For the analysed period (1991-2019), the highest number of citations was achieved in 2019 (821 citations), a significant increase compared to previous years, 2018 or 2017.

An in-depth analysis of citations, table 3 presents the first 10 published studies that recorded the highest number of citations. The most cited paper is written by Chen, Greene, and Crick (1998) and recorded a total of 894 citations (with an average of 38.87 citations/year). It is worth mentioning that this paper is published in the Journal of Business Venturing. The same journal also published the next most cited paper, Cliff (1998), which has a total of 327 citations (an average of 14.22 citations/year) and the paper that holds the position 6 in table 3, respectively Douglas and Shepherd (2000), has a 


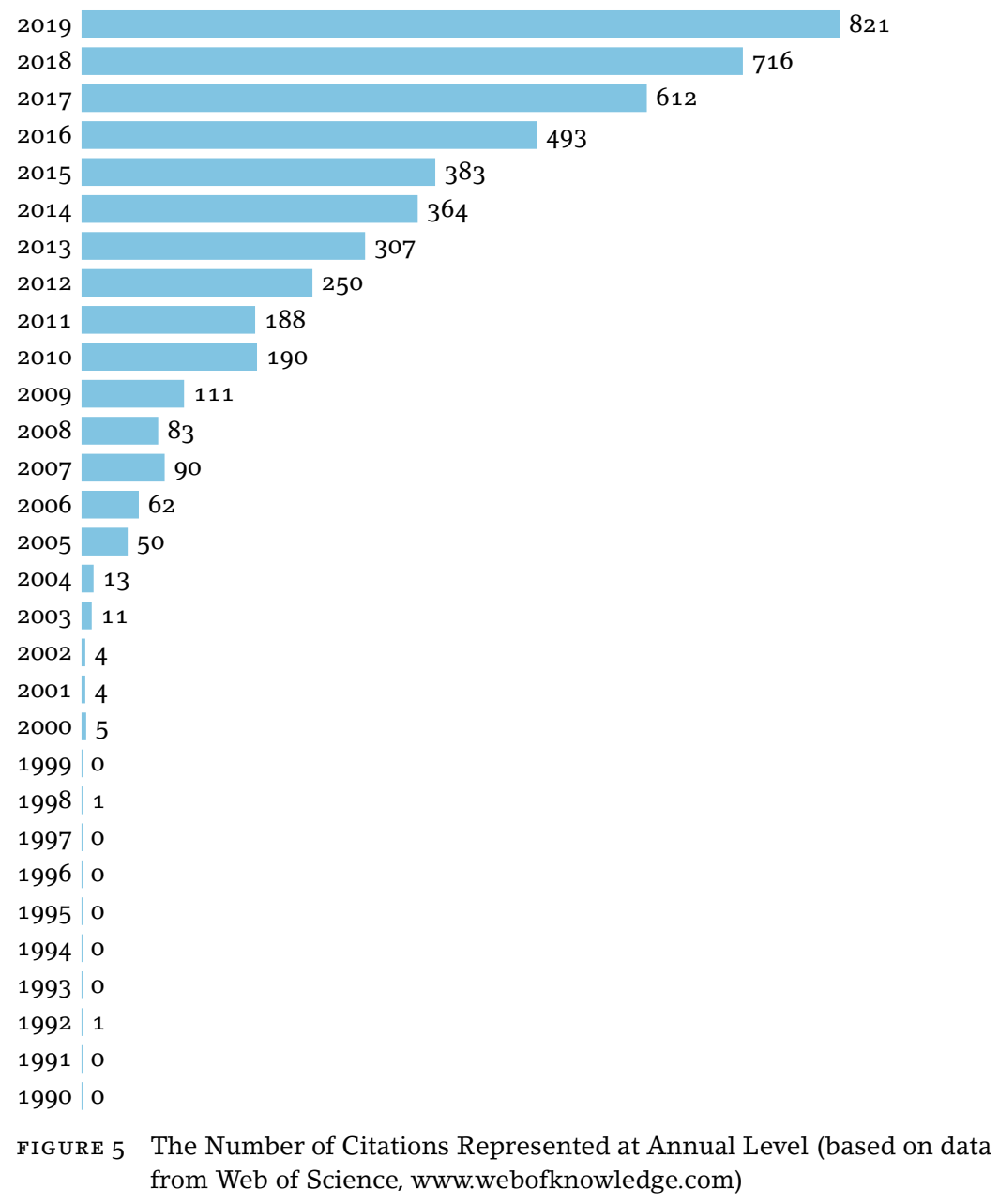

total of 175 citations (8.33 citations/year). The journal ranked 1st in table 1, Small Business Economics, occupies two positions in table 3, with the studies of Caliendo, Fossen and Kritikos (2009), and Grilo and Irigoyen (2006).

We have to mention that none of the authors from table 2 (the first 15 authors with the most publications targeted by this analysis), was not among the studies with the highest number of citations. Also, neither the journals with the highest number of publications isn't in this ranking. In contrast, Annals of Regional Science published the paper ranked 7 th in table 2 with the paper by Wagner and Sternberg (2004), which recorded 153 citations (an average of 9.00 cita- 


\begin{tabular}{|c|c|c|c|}
\hline Title & Authors & (1) & $(2)$ \\
\hline $\begin{array}{l}\text { Does Entrepreneurial Self-Efficacy Distin- } \\
\text { guish Entrepreneurs from Managers? }\end{array}$ & $\begin{array}{l}\text { Chen, Greene, and } \\
\text { Crick (1998) }\end{array}$ & 894 & 38.87 \\
\hline $\begin{array}{l}\text { Does One Size Fit All? Exploring the Rela- } \\
\text { tionship between Attitudes towards Growth, } \\
\text { Gender, and Business Size }\end{array}$ & Cliff (1998) & 327 & 14.22 \\
\hline $\begin{array}{l}\text { Low Risk Aversion Encourages the Choice for } \\
\text { Entrepreneurshi }\end{array}$ & Cramer et al. (2002) & 183 & 9.63 \\
\hline $\begin{array}{l}\text { Entrepreneurial Orientation of smEs, Product } \\
\text { Innovativeness, and Performance }\end{array}$ & $\begin{array}{l}\text { Avlonitis and } \\
\text { Salavou (2007) }\end{array}$ & 181 & 12.93 \\
\hline $\begin{array}{l}\text { Risk Attitudes of Nascent Entrepreneurs: } \\
\text { New Evidence from an Experimentally Vali- } \\
\text { dated Survey }\end{array}$ & $\begin{array}{l}\text { Caliendo, Fossen, } \\
\text { and Kritikos (2009) }\end{array}$ & 178 & 14.83 \\
\hline $\begin{array}{l}\text { Entrepreneurship as a Utility Maximizing Re- } \\
\text { sponse }\end{array}$ & $\begin{array}{l}\text { Douglas and Shep- } \\
\text { herd (2000) }\end{array}$ & 175 & 8.33 \\
\hline $\begin{array}{l}\text { The Roots of Entrepreneurship and Labour } \\
\text { Demand: Individual Ability and Low Risk } \\
\text { Aversion }\end{array}$ & $\begin{array}{l}\text { Van Praag and } \\
\text { Cramer (2001) }\end{array}$ & 154 & $7 \cdot 70$ \\
\hline $\begin{array}{l}\text { Start-up Activities, Individual Characteristics, } \\
\text { and the Regional Milieu: Lessons for Entre- } \\
\text { preneurship Support Policies from German } \\
\text { Micro Data }\end{array}$ & $\begin{array}{l}\text { Wagner and Stern- } \\
\text { berg (2004) }\end{array}$ & 153 & 9.00 \\
\hline $\begin{array}{l}\text { Entrepreneurship in the } \mathrm{E} \mathrm{U} \text { : To Wish and Not } \\
\text { to Be }\end{array}$ & $\begin{array}{l}\text { Grilo and Irigoyen } \\
(2006)\end{array}$ & 143 & 9.53 \\
\hline $\begin{array}{l}\text { Entrepreneurial Interest of University Stu- } \\
\text { dents in Singapore }\end{array}$ & $\begin{array}{l}\text { Wang and Wong } \\
(2004)\end{array}$ & 141 & 8.29 \\
\hline
\end{tabular}

Notes Column headings are as follows: (1) number of citations, (2) average number of citations. Based on data from Web of Science (www.webofknowledge.com).

tions/year), 10 citations more than the paper done by the authors Grilo and Irigoyen (2006) from Small Business Economics magazine, which has the most publications of interest according to table 1.

As shown in table 4 of the top 10 most cited studies, some papers have started to be cited from 2000 (Chen, Greene, and Crick), and the rest of the studies since 2009. However, the number of citations has increased significant since 2013, and continuing to grow since then with slight fluctuations depending on the area of interest of the researchers.

\section{Keywords Analysis}

The keyword analysis is based on the centralization of all 6594 keywords within all 295 papers. In order to carry out an in-depth analysis, both the keywords proposed by the authors and the keywords 
TABLE 4 Citations Received by Year

\begin{tabular}{|c|c|c|c|c|c|c|c|c|c|c|}
\hline Year & (1) & (2) & (3) & (4) & (5) & (6) & (7) & (8) & (9) & (10) \\
\hline 2000 & 5 & o & o & o & o & o & o & 0 & o & 0 \\
\hline 2001 & 2 & 2 & o & o & O & 0 & o & o & o & $\mathrm{O}$ \\
\hline 2002 & 1 & 2 & o & o & O & 1 & o & o & o & 0 \\
\hline 2003 & 6 & 3 & o & o & O & 2 & o & o & o & o \\
\hline 2004 & 8 & 1 & 1 & o & O & 2 & o & 1 & o & o \\
\hline 2005 & 21 & 10 & 4 & o & o & 4 & 5 & 4 & o & 1 \\
\hline 2006 & 18 & 20 & 5 & o & O & 2 & 7 & 7 & o & 2 \\
\hline 2007 & 25 & 17 & 7 & o & o & 6 & 7 & 10 & 6 & 7 \\
\hline 2008 & 30 & 13 & 5 & 1 & o & 3 & 5 & 3 & 9 & 5 \\
\hline 2009 & 33 & 14 & 5 & 4 & 1 & 2 & 3 & 6 & 8 & 7 \\
\hline 2010 & 44 & 25 & 14 & 7 & 9 & 13 & 12 & 9 & 14 & 7 \\
\hline 2011 & 42 & 11 & 12 & 17 & 9 & 9 & 15 & 11 & 12 & 10 \\
\hline 2012 & 56 & 23 & 9 & 16 & 20 & 15 & 9 & 12 & 10 & 9 \\
\hline 2013 & 77 & 27 & 13 & 15 & 13 & 18 & 13 & 14 & 13 & 4 \\
\hline 2014 & 66 & 16 & 29 & 25 & 22 & 9 & 19 & 15 & 14 & 11 \\
\hline 2015 & 90 & 23 & 14 & 15 & 17 & 17 & 15 & 7 & 13 & 15 \\
\hline 2016 & 76 & 25 & 13 & 23 & 27 & 15 & 9 & 18 & 10 & 18 \\
\hline 2017 & 91 & 31 & 18 & 21 & 17 & 14 & 11 & 16 & 15 & 15 \\
\hline 2018 & 90 & 35 & 16 & 17 & 22 & 28 & 11 & 12 & 11 & 18 \\
\hline 2019 & 110 & 28 & 16 & 20 & 21 & 15 & 13 & 8 & 8 & 12 \\
\hline
\end{tabular}

nотеs Column headings are as follows: (1) Chen, Greene, and Crick (1998), (2) Cliff (1998), (3) Cramer et al. (2002), (4) Avlonitis and Salavou (2007), (5) Caliendo, Fossen, and Kritikos (2009), (6) Douglas and Shepherd (2000), (7) Van Praag and Cramer (2001), (8) Wagner and Sternberg (2004), (9) Grilo and Irigoyen (2006), (10) Wang and Wong (2004). Based on data from Web of Science (www.webofknowledge.com).

added by the web of Science were included in the indexing of each paper.

The first stage of this analysis involved extracting all the information from the Web of Science database, selecting all the information relevant to the study (authors' names, title of the paper, abstract, year of publication and keywords), and then exporting them to the desired format for the program vosviewer (Clarivate Analytics 2019). Subsequently, they were introduced into the program that selected automatically the keywords based on their frequency and relevance for the case study conducted (Jan Van Eck and Waltman 2019; Gora 2019; Marinescu, Cicea, and Colesca 2019). Given the program setting that allows you to manually select the desired frequency, we reduced the number of keywords in order to minimize the number of keywords to only those that had a minimum of 10 occurrences. This 
TABLE 5 The List of Keywords Analysed Based on Occurrence and Relevance

\begin{tabular}{|c|c|c|c|c|c|}
\hline Keyword & (1) & (2) & Keyword & (1) & (2) \\
\hline risk attitude & 45 & 2.29 & field & 22 & 0.41 \\
\hline skill & 41 & 0.53 & $\operatorname{man}$ & 22 & 1.75 \\
\hline decision & 40 & 1.17 & creativity & 21 & 1.18 \\
\hline firm & 40 & 1.52 & employment & 21 & 0.79 \\
\hline knowledge & 40 & 0.41 & technology & 21 & 1.12 \\
\hline entrepreneurial intention & 39 & 2.07 & entrepreneurial orientation & 20 & 2.23 \\
\hline performance & 36 & 0.83 & goal & 20 & 0.84 \\
\hline woman & 35 & 0.89 & probability & 19 & $3 \cdot 98$ \\
\hline culture & 32 & 0.58 & region & 19 & 0.45 \\
\hline growth & 32 & 0.77 & economic development & 18 & 0.49 \\
\hline variable & 30 & 0.52 & own business & 17 & 0.58 \\
\hline willingness & 30 & 0.61 & employee & 16 & 1.53 \\
\hline control & 29 & 0.87 & uncertainty & 16 & 0.63 \\
\hline market & 28 & 0.65 & achievement & 15 & 1.13 \\
\hline preference & 28 & 2.54 & organization & 15 & 2.39 \\
\hline gender & 27 & 0.69 & economic growth & 14 & 0.63 \\
\hline risk aversion & 27 & 2.80 & effort & 14 & 0.43 \\
\hline self-employment & 27 & 2.30 & entrepreneurial skill & 14 & 1.08 \\
\hline enterprise & 26 & 0.62 & income & 14 & 0.72 \\
\hline management & 26 & 0.83 & personality trait & 13 & 1.16 \\
\hline innovativeness & 25 & 0.61 & SMES & 13 & 1.43 \\
\hline resource & 25 & 0.30 & account & 12 & 1.06 \\
\hline age & 24 & 1.58 & barrier & 12 & 0.47 \\
\hline behaviour & 24 & 0.58 & entrepreneurial behaviour & 12 & 1.28 \\
\hline manager & 24 & 1.32 & evaluation & 12 & 1.34 \\
\hline entrepreneurship education & 23 & 1.23 & positive attitude & 12 & 0.60 \\
\hline failure & 23 & 0.97 & policy maker & 11 & 0.67 \\
\hline problem & 23 & 0.34 & financial risk & 10 & 1.09 \\
\hline degree & 22 & 0.60 & & & \\
\hline
\end{tabular}

Notes Column headings are as follows: (1) occurrences, (2) relevance. Based on data from Web of Science (www.webofknowledge.com).

filtering resulted in 193 keywords to be analysed, out of which 77 keywords were considered to be the most relevant keywords. Based on the relevance considered by the authors, they were restricted to 57 keywords. Based on table 5, which presents the keywords sorted by the frequency of use and their relevance for the current study, the keywords were grouped into clusters according to the vos clustering technique explained by the authors of the manual (Jan Van Eck and Waltman 2019). 


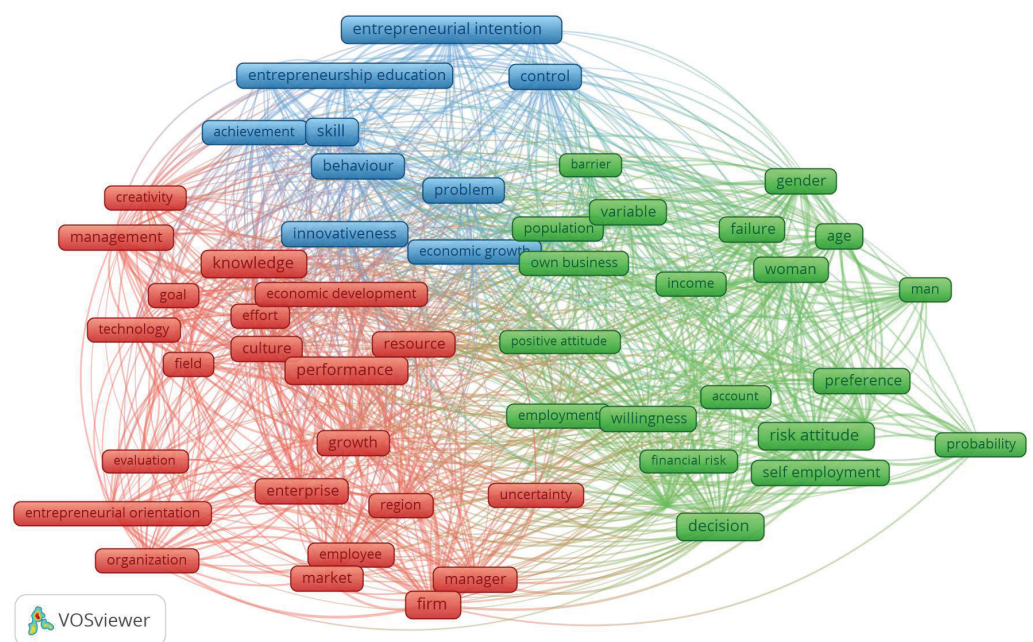

FIGURE 6 Keyword Map Based on Links (created with the vosviewer)

Regarding the vos clustering technique, as other specialists have done (Gora 2019; Marinescu, Cicea, and Colesca 2019; Jan Van Eck and Waltman 2019), we used the number of nodes (keywords), the links between them, the total number of links and the total force between them. Thus, starting from this information, for each node has been calculated the distance from the other nodes and for each of these nodes has been subsequently positioned in a two-dimensional space (a mapping type representation).

The synthesis of the previous information can be found in figure 6 , which shows the mapping view of the 57 keywords presented in table 5. Figure 6 shows the 57 nodes (the keywords found in at least 10 of the analysed studies that has been presented in table 5), The links between the nodes from the map are made according to their frequency in the studies, and the size of a node is influenced by the frequency of its use as a keyword or by the number of keywords found within it. Based on the information found in both figure 6 and table 5, we can conclude that the largest node is 'risk attitude,' but the highest frequency is 'entrepreneurial' with the frequency of 85 occurrences ('entrepreneurial behaviour' - 12 uses; 'entrepreneurial intention' - 39 uses; 'entrepreneurial orientation' - 20 uses; 'entrepreneurial skill' - 14 uses). The result is expected given the fact that those keywords are defining for the topic being treated.

Regarding the cluster analysis of the 57 keywords, the program 


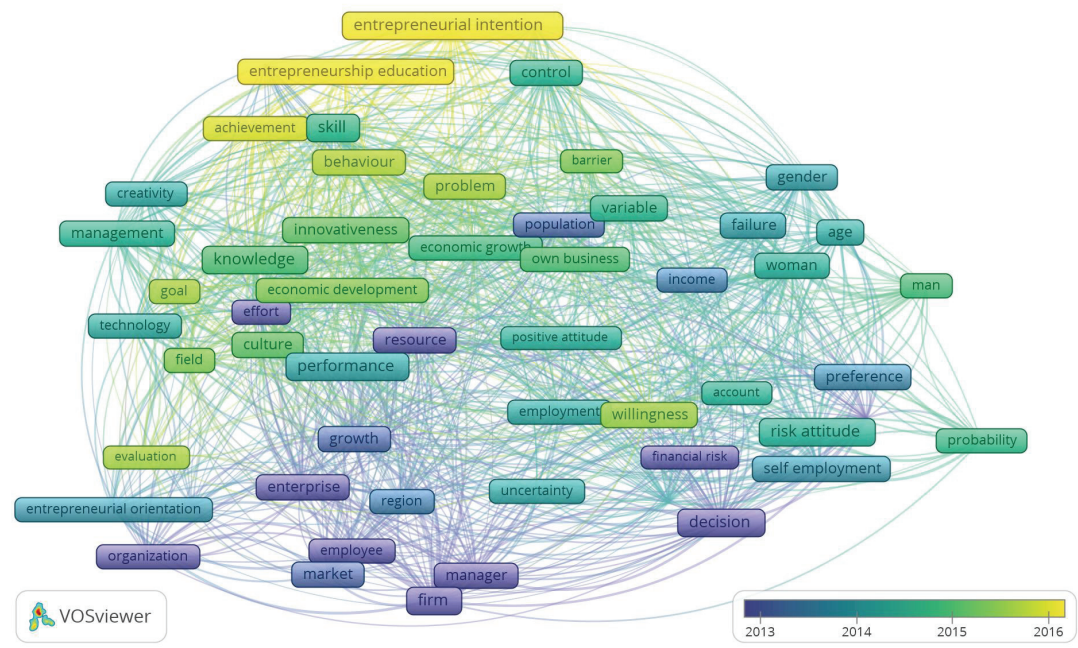

FIGURE 7 Keyword Map Based on Their Frequency on a Period of Time (created with the vosviewer)

grouped the keywords into 3 clusters highlighted with different colours (red, green and blue). According to the visual representation in figure 6, the words highlighted in red have the most keywords (24 nodes), followed by the green ones (21 nodes) and the few ones are grouped in the blue colour ( 12 nodes).

The connections between the nodes on the map are made in the form of curves of different sizes. These dimensions are influenced by the frequency of using that link between nodes. Also, this links also influence the positioning of the nodes on the map; the closer they are, the stronger the connection between them. According to figure 6 , the most common links are created between words such as 'risk attitude,' 'decision,' 'firm,' 'knowledge,' 'entrepreneurial intention,' 'performance,' 'culture,' 'resource' and 'skill.'

Furthering in this analysis we have made a representation of these nodes based on the periods of time from which they began to be used. The graphic from figure 7 shows a difference in the representation of the nodes on the map. The connections between them are also based on curves of different sizes, but those are influenced by the period of time from when they were used. Their positioning on the map is achieved by the strength of the link. The program grouped the keywords into 3 clusters, and their color is influenced by the period of time from when they were predominantly used. The 3 clusters 
are grouped as follows: on the left side of the figure are the nodes in cluster 1 (24 keywords), on the left are grouped nodes in cluster 2 (21 keywords), and in the upper part, the most few knots (12 keywords).

In this analysis we observe changes in the research fields as the specialists have reoriented their research area. In the period 20132014, the specialists used in their studies keywords such as 'organization,' 'market,' 'firm,' 'decision, 'financial risk,' 'enterprise,' 'effort,' 'population,' 'resource.' Subsequently, in the period 2014-2015, the focus was placed on keywords such as 'uncertainty,' 'entrepreneurial orientation,' 'gender,' 'account,' 'employment,' 'performance,' 'management,' 'risk attitude,' 'creativity,' 'skill.' The lightest colours are used in the period 2015-2016. Within this period there can be found words like: 'entrepreneurship education,' 'entrepreneurial intention,' 'achievement,' 'goal,' 'behaviour,' 'field,' 'innovativeness,' 'knowledge,' 'culture,' 'evaluation,' 'willingness,' 'barrier,' 'problem,' 'economic growth,' 'own business.'

\section{Conclusions}

Entrepreneurship is a key activity in the process of sustainable development of the economy, and has an important contribution to the process of innovation. Furthermore it is perceived as a risky activity, which has led many scholars to focus on studying the different aspects of the risk - entrepreneurship relationship.

Subsequent to analysing the role of risk management in the entrepreneurial activity, the researches focused on correlating the risk attitude with the entrepreneurship activity both through the performance of the obtained results and as influence on the decisions of the entrepreneurs. Thus, this paper, based on the bibliometric analysis of all the papers resulting from the query of the Web of Science database using the keywords 'risk attitude' and 'entrepreneurship,' analyses the number of papers, the top authors most interested in researching the influence of the risk attitude in the entrepreneurial activity, the journals with the highest contributions, the period of time in which the most studies and citations were performed, but also the most common keywords used by specialists.

The research results showed that the period in which the researchers have done the highest number of papers and have quoted the most number of papers is 2016-2019. The most significant contributions to this research area were made by Small Business Economics journal. From the analysis of the authors of the studies it was found that Frossen Frank M. and Thurik Roy, two university professors, contributed with the most studies, but, cumulatively, the highest 
share of the number of studies has been done by European authors (61.55\% of the total analysed studies).

By analysing the keywords based on the vosviewer program, we highlighted the direction in which the interest of the researchers has been oriented over time. During 2013-2014 they analysed the market, the financial risks, the effort made by the entrepreneurs, the influence of the pollution, the allocated resources, and from 2014 to 2015, the researchers orientation deepened on studying the structure of the companies, the decisions taken under conditions of uncertainty, the financial performance, the influence of the entrepreneur's gender in the activity of the enterprise. Subsequent to 2015, the researchers focused on analysing the influence of entrepreneurial education, innovation, culture, as well as the barriers that entrepreneurs encounter in reaching their goals. Therefore, now, the interest of the researchers tends to analyses the criteria underlying the decisions taken, the knowledge that the entrepreneurs have, the correlation between risk-entrepreneurship-performance, the impact of culture, the use of resources for a sustainable development, and also the main features of the entrepreneurs who represent characteristics of their attitude towards risk.

The current case study has certain limitations due to the processed information only from a single database (Web of Science) that have been filtered (selecting only the articles, review and proceedings paper from 1990-2019). This study, analysis the publications up to 2019, may be useful to other researchers who wish to further analyse the influence of the risk attitude in the entrepreneurial activity and may suggest future research directions, but also to identify the topics and the publications with the greatest impact.

\section{Acknowledgements}

This study is the result of the research carried out within the doctoral studies programs of the Bucharest University of Economic Studies, Doctoral School of Management.

\section{References}

Aparicio, G., T. Iturralde, and A. Maseda. 2019. 'Conceptual Structure and Perspectives on Entrepreneurship Education Research: A Bibliometric Review.' European Research on Management and Business Economics 25 (3): 105-13.

Bartolacci, F., A. Caputo, and M. Soverchia. 2020. 'Sustainability and Financial Performance of Small and Medium Sized Enterprises: A Bibliometric and Systematic Literature Review.' Business Strategy and the Environment 29 (3): 1297-1309. 
Berbegal-Mirabent, J., I. Alegre, and D. Ribeiro-Soriano. 2018. 'Entrepreneurship in the Middle East and North Africa: A Bibliometric Analysis.' In Entrepreneurship Education and Research in the Middle East and North Africa, edited by N. Faghih and M. Zali, 273-90. Cham: Springer. https://doi.org/10.1007/978-3-319-90394-1_15

Block, J., P. Sander, and F. Spiegel. 2015. 'How Do Risk Attitudes Differ Within The Group Of Entrepreneurs?' Journal of Small Business Management 53 (1): 183-206.

Bosma, N. S., T. Schøtt, S. A. Terjesen, and P. Kew. 2016. Global Entrepreneurship Monitor. https://www.gemconsortium.org/report/gem -2015-report-on-social-entrepreneurship

Brustbauer, J. 2014. 'Enterprise Risk Management in smes: Towards a Structural Model.' International Small Business Journal 34 (1): 70-85.

Burmeister-Lamp, K., M. Lévesque, and C. Schade. 2012. 'Are Entrepreneurs Influenced by Risk Attitude, Regulatory Focus or Both?' Journal of Business Venturing 27 (4): 456-76.

Caliendo, M., F. Fossen, and A. Kritikos. 2006. 'Risk Attitudes of Nascent Entrepreneurs: New Evidence from an Experimentally Validated Survey.' Discussion Paper 252, European University Viadrina, Frankfurt.

. 2010. 'The Impact of Risk Attitudes on Entrepreneurial Survival.' Journal of Economic Behavior and Organization 76 (1): 45-63.

Cantillon, R. 2010. An Essay on Economic Theory. Auburn, AL: Ludwig von Mises Institute.

Chiţimiea, A., C. N. Ciocoiu, V. R. Văduva (Opriţa), and N. Moroianu. 2019. 'Entrepreneurship in Europe: Approaches, Evolution and Trends.' In Proceedings of the 13th International Management Conference: Management Strategies for High Performance, edited by I. Popa, C. Dobrin, and C. N. Ciocoiu, 1093-106. http://conference .management.ase.ro/archives/2019/pdf/5_11.pdf

Clarivate Analytics. 2019. 'Web of Science Core Collection: Exporting Author Keywords to Refpapers.' https://support.clarivate.com/ ScientificandAcademicResearch/s/article/Web-of-Science-Core -Collection-Exporting-Author-Keywords-to-Refpapers?language =en_US

Cliff, J. 1998. 'Does One Size Fit All? Exploring the Relationship between Attitudes towards Growth, Gender, and Business Size.' Journal of Business Venturing 13 (16): 523-42.

Cramer, J. S., J. Hartog, N. Jonker, and C. M. Van Praag. 2002. ‘Low Risk Aversion Encourages the Choice for Entrepreneurship: An Empirical Test of a Truism.' Journal of Economic Behavior \& Organization $48(1): 29-36$.

Dan, M. C., and S. I. Goia. 2018. 'Entrepreneurship and Regional Development: A Bibliometric Analysis.' Proceedings of the International Conference on Business Excellence 12 (1): 276-87. 
Dawson, C. G., and A. Henley. 2015. 'Gender, Risk and Venture Creation Intentions.' Journal of Small Business Management 53 (2): 501-15.

Dionisio, M. 2019. 'The Evolution of Social Entrepreneurship Research: A Bibliometric Analysis.' Social Enterprise Journal 15 (1): 22-45.

Draheim, K. P. 1972. 'Factors Influencing the Rate of Formation of Technical Companies.' Technical Entrepreneurship: A Symposium, edited by A. C. Cooper and J. L. Komives, 3-27. Milwaukee, wi: Center for Venture Management.

Elam, A. B., C. G. Brush, P. G. Greene, B. Baumer, M. Dean, and R. Heavlow. 2019. Global Entrepreneruship Monitor: 2018-2019 Women's Entrepreneurship Report. https://www.gemconsortium.org/report/ gem-20182019-womens-entrepreneurship-report

Folta, T. B., F. Delmar, and K. Wennberg. 2010. 'Hybrid Entrepreneurship.' Management Science 56 (2): 253-69.

Georgalos, K. 2017. 'Entrepreneurship Under Risk and Uncertainty: A Review of the Experimental Evidence.' In Inside the Mind of the Entrepreneur: Contributions to Management Science, edited by A. Tur Porcar and D. Ribeiro Soriano, 59-74. Cham: Springer.

Gora, A. A. 2019. 'The Link between Decision Making Process and Performance: A Bibliometric Analysis.' Management and Economics Review 4 (2): 177-91.

Hanggraeni, D., B. Slusarczyk, L. A. K. Sulung, and A. Subroto. 2019. 'The Impact of Internal, External and Enterprise Risk Management on the Performance of Micro, Small and Medium Enterprises.' Sustainability 11 (7): 1-17.

Jan Van Eck, N., and L. Waltman. 2019. 'vosviewer Manual.' https:// www.vosviewer.com/documentation/Manual_VOSviewer_1.6.10.pdf

Kihlstrom, R. E., and J. J. Laffont. 1979. 'A General Equilibrium Entrepreneurial Theory of Firm Formation Based on Risk Aversion.' The Journal of Political Economy 87 (4): 719-48.

Kirzner, I. M. 1973. Competition and Entrepreneurship. Chicago: University of Chicago Press.

Knight, F. H. 1921. 'Risk, Uncertainty and Profit.' https://ssrn.com/ abstract $=1496192$

Lampe, J., P. S. Kraft, and A. Bausch. 2019. 'Mapping the Field of Research on Entrepreneurial Organizations (1937-2016): A Bibliometric Analysis and Research Agenda.' Entrepreneurship Theory and Practice 44 (4): 1-33.

Marinescu, C., C. Cicea, and S. E. Colesca. 2019. 'Tracking BiofuelsInnovation Relationship through Scientific and Technological Advances.' Management Research and Practice 11 (2): 31-44.

Michl, T., I. M. Welpe, M. Sporrle, and A. Picot. 2009. 'The Role of Emotions and Cognitions in Entrepreneurial Decision-Making.' In Understanding the Entrepreneurial Mind, edited by M. Brännback and A. Carsrud, 167-90. Cham: Springer. 
Rauch, A., and M. Frese. 2007. 'Let's Put the Person Back into Entrepreneurship Research: A Meta-Analysis on the Relationship between Business Owners' Personality Traits, Business Creation, and Success.' European Journal of Work and Organizational Psychology 16 (4): 353-85.

Servantie, V., M. Cabrol, G. Guieu, and J. P. Boissin. 2016. 'Is International Entrepreneurship a Field? A Bibliometric Analysis of the Literature (1989-2015).' Journal of International Entrepreneurship 14 (2): 168-212.

Thananusak, T. 2019. 'Science Mapping of the Knowledge Base on Sustainable Entrepreneurship, 1996-2019.' Sustainability 11 (13): 1-20.

Yang, S., M. Ishtiaq, and M. Anwar. 2018. 'Enterprise Risk Management Practices and Firm Performance, the Mediating Role of Competitive Advantage and the Moderating Role of Financial Literacy.' Journal of Risk and Financial Management 11 (35): 1-17.

Zheng, Y. 2018. 'The Past, Present and Future of Research on Chinese Entrepreneurship Education: A Bibliometric Analysis Based on cssci Journal Articles.' Educational Sciences: Theory \& Practice $18(5): 1255^{-76}$. 